\title{
Probing the Competition among Different Coordination Motifs in Metal-Ciprofloxacin Complexes through IRMPD Spectroscopy and DFT Calculations
}

\author{
Susanna Piccirillo, ${ }^{\dagger}$ Alessandra Ciavardini, ${ }^{\dagger,}$ Enrico Bodo, ${ }^{\S}$ Flaminia Rondino, ${ }^{\dagger, \#}$ Debora Scuderi, ${ }^{\|}$ \\ Vincent Steinmetz," and Alessandra Paladini*, ${ }^{\perp}$ \\ ${ }^{\dagger}$ Dip. di Scienze e Tecnologie Chimiche, Università di Roma "Tor Vergata", via della Ricerca Scientifica, 00133 Rome, Italy \\ "Dip. di Chimica e Tecnologie del Farmaco, Università di Roma "La Sapienza", p.le A. Moro 5, 00185 Rome, Italy \\ ${ }^{\S}$ Dip. di Chimica, Università di Roma "La Sapienza", p.le A.Moro 5, 00185 Rome, Italy \\ "Laboratoire de Chimie Physique, Université Paris Sud 11, UMR 8000, 91405 Orsay Cedex, France \\ ${ }^{\perp} \mathrm{CNR}$ - Istituto di Metodologie Inorganiche e dei Plasmi, via Salaria km 29.300, Monterotondo (RM), Italy
}

\section{Supporting Information}

ABSTRACT: The vibrational spectra of ciprofloxacin complexes with monovalent $\left(\mathrm{Li}^{+}, \mathrm{Na}^{+}, \mathrm{K}^{+}, \mathrm{Ag}^{+}\right)$and polyvalent $\left(\mathrm{Mg}^{2+}, \mathrm{Al}^{3+}\right)$ metal ions are recorded in the range $1000-1900 \mathrm{~cm}^{-1}$ by means of infrared multiplephoton dissociation (IRMPD) spectroscopy. The IRMPD spectra are analyzed and interpreted in the light of density functional theory (DFT)based quantum chemical calculations in order to identify the possible structures present under our experimental conditions. For each metalciprofloxacin complex, four isomers are predicted, considering different chelation patterns. A good agreement is found between the measured IRMPD spectrum and the calculated absorption spectrum of the most stable isomer for each complex. Metal ion size and charge are found to drive the competition among the different coordination motifs: small size and high charge density metal ions prefer to coordinate the quinolone

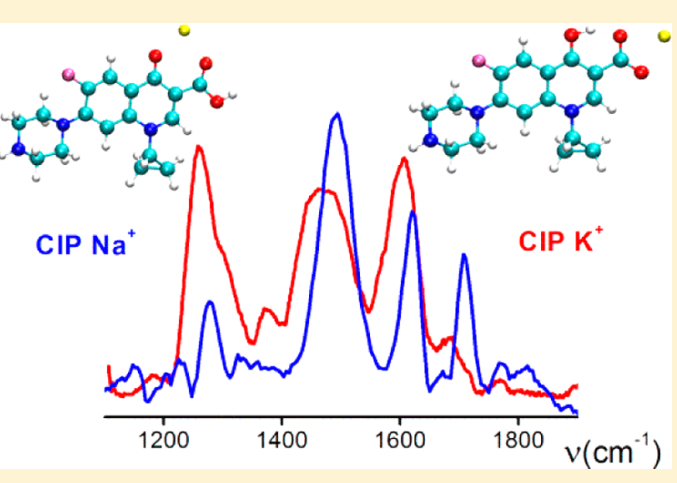
between the two carbonyl oxygen atoms, whereas large-size metal ions prefer the carboxylate group as a coordination site. In the latter case, an intramolecular hydrogen bond compensates the weaker interaction established by these cations. The role of the metal cation on the stabilization of ionic and nonionic structures of ciprofloxacin is also investigated. It is found that large-size metal ions preferentially stabilize charge separated motifs and that the increase of metal ion charge has a stabilizing effect on the zwitterionic form of ciprofloxacin.

\section{INTRODUCTION}

Quinolone antibiotics play an important role in the treatment of serious bacterial infections. The mechanism of their antibacterial action is different from those antibiotics that target the bacterial cell wall, such as penicillins and cephalosporins, and is believed to stem from a combination of the ability to penetrate into bacterial cells and to inhibit DNA gyrase and topoisomerase IV key enzymes. These enzymes dictate the DNA conformation and allow it to be properly stored, unwound, replicated, repaired and transcribed. $^{1-3}$ In particular, quinolones seem to alter the DNA twisting degree, releasing torsional stress in the molecule and thereby making a cell's DNA inaccessible and eventually leading to cell death.

A variety of medications containing metal ions have been shown to interfere with the pharmacological activity of quinolones and decrease their bioavailability. Clinically relevant drug-drug interactions between quinolones and metal cations have been described in the last decades, ${ }^{4-7}$ but the biopharmaceutical mechanism of this interaction is still not understood. One of the main disagreements in the pertaining literature concerns the effect of metal cations on the solubility of quinolones, namely, metal cations are reported to increase as well as to decrease the solubility of quinolones, affecting their bioavailability.

There are two possible mechanisms that would explain the reduction of quinolone's activity in the presence of metal cations. One possible reason is that the higher ionic charge, polarity, and hydrophilicity of metal chelates may reduce the ability of the antibiotic to permeate across the lipophilic bacterial cell membrane. The second possible reason is that the formation of the chelate may result in the lack of any antibacterial activity. Up to date, this topic remains intensely debated.

Received: June 19, 2012

Published: December 20, 2012 
Since the pharmacological activity greatly depends on the degree of ionization, lipophilicity, and conformational characteristics, it is important to evaluate the structural factors that could contribute to the drug properties and the extent of its interaction with metals. In recent years, there has been an extensive scientific activity in order to improve the identification and quantification of metal-biomolecule adducts using novel methodologies. The advent of electrospray ionization (ESI) has spawned enormous advances in the structural characterization of molecules of biological and pharmacological interest. In fact, solution-phase molecules and their complexes can be directly transferred by ESI into the gas phase, where they can be investigated using mass spectrometry and laser spectroscopy.

While it can be argued that the gas-phase studies are not directly related to the drug's biological activity because the latter takes place in the bulk phase, it is nevertheless true that the study of gas-phase molecular aggregates is of paramount importance in understanding their binding properties and in obtaining a better characterization of their structural related properties and biological activities. In particular, the absence of a solvent medium allows establishing, within the intrinsic limits of the experimental/theoretical techniques, the unperturbed nature of the bound complex and of its binding forces. This knowledge may help in obtaining a better understanding of the complex solvent effects, which would otherwise be extremely difficult to individuate. Furthermore, the results of gas-phase experiments can be used by theoretical chemists as a benchmark for the validation of different approximations for $\mathrm{ab}$ initio calculations.

A well-established powerful approach for structural characterization of ESI-generated, mass-selected ions is infrared multiplephoton dissociation (IRMPD) spectroscopy, aided by the availability of widely tunable and powerful sources of IR radiation such as free electron lasers (FEL) $)^{8,9}$ and optical parametric oscillator/amplifier (OPO/OPA) laser sources. ${ }^{10,11}$ For this reason, this experimental approach has been successfully applied to a variety of proton or metal cationized biomolecular systems, ${ }^{9,12-22}$ including amino acids, peptides, proteins, nucleotides, and oligosaccharides.

Ciprofloxacin (CIP), one of the most popular drugs of the class of quinolone antibiotics, is a second generation fluoroquinolone antimicrobial agent, with a broad spectrum of activity against common aerobic Gram-negative and Grampositive bacterial pathogens. It is well known that CIP absorption decreases when coadministered with magnesiumaluminum antacids, following inhibition of its metabolism. Other cations such as calcium, iron, and probably zinc appear to interact in a similar manner.

In a previous paper, ${ }^{23}$ we measured the IRMPD spectrum of $\mathrm{CIPH}^{+}$and assigned it to the isomer with protonation occurring at the piperazinyl amino group, which is not predicted as the most stable structure in the gas phase. This has been rationalized by assuming that this protonation, typical of the zwitterionic form in protic solvents, is retained in the ESI process. It is well-known that populations of ions formed by the ESI process may reflect structures that are present in solution, which are thermodynamically disfavored in the gas phase. ${ }^{24,25}$ When numerous isomers can be present, it is therefore of utmost importance to characterize the gas-phase complexes both at the experimental and theoretical level, in order to obtain a reliable description of the unperturbed situation and to assess the role of the solvent effect.
In this work, we report on gas-phase IRMPD spectroscopic studies of complexes of CIP with several monovalent $\left(\mathrm{Li}^{+}, \mathrm{Na}^{+}\right.$, $\left.\mathrm{K}^{+}, \mathrm{Ag}^{+}\right)$and polyvalent $\left(\mathrm{Mg}^{2+}, \mathrm{Al}^{3+}\right)$ metal cations in order to investigate the influence of metal cation size and charge on the competition among different chelation patterns. Since this molecule not only may exist in neutral or zwitterionic form but presents also different binding sites for the metal ions, it is of interest to investigate the role played by the solvent in inducing a stabilization of specific isomers of the CIP metal complexes. The IRMPD spectra have been analyzed and interpreted in the light of density functional theory (DFT)-based quantum chemical calculations.

\section{THEORETICAL AND EXPERIMENTAL METHODS}

Computational Details. The CIP isomeric structures have been taken from our previous paper. ${ }^{23}$ The structures with the added metal ions have then been reoptimized at the B3LYP/6-311+G(d,p) level using Gaussian09. ${ }^{26}$ In the CIP molecule, we have identified two possible coordination sites by the metal ion (see Figure 1):

- One is the position between the two carbonyl oxygen atoms, where the metal acts as a sort of chelate ligand (structure $\mathbf{M}$ ). A variation of this structure is obtained by moving the $\mathrm{COOH}$ proton onto the NH piperazinyl group (structure $\mathrm{Z1}$ ).

- The other coordination site for the metal ion is the deprotonated $\mathrm{CO}_{2}^{-}$terminal. The resulting proton can then be linked either on the adjacent carbonyl (quinolone carbonyl) (structure SC) or to the piperazinyl nitrogen atom on the other side of the molecule (structure $\mathbf{Z 2}$ ).

Each of these four possibilities have been investigated for each of the metal cations: we have optimized the resulting geometry at the

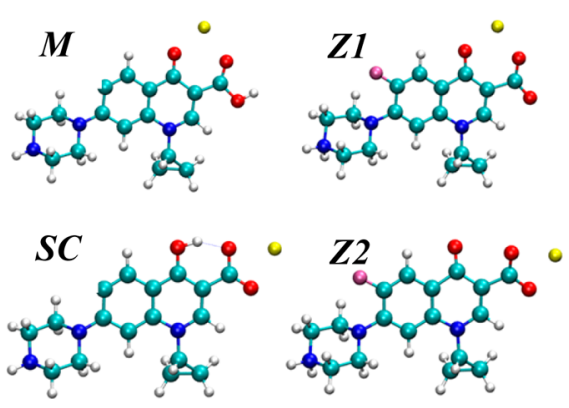

Figure 1. Structural motifs for the most stable metal cation complexes of CIP (by those for CIP $\mathrm{Na}^{+}$) calculated at the B3LYP/6-311+G(d,p) level of theory.

B3LYP $/ 6-311+G(d, p)$ level, and we have calculated the vibrational infrared spectra, the relative energies, and the relative free energies at $298 \mathrm{~K}$ using the harmonic approximation. The four structures for the $\mathrm{Na}^{+}$case are shown in Figure 1.

The computed vibrational IR spectra were scaled by 0.98 in accord with previous IRMPD investigations of cationized amino acids and peptides in the same wavelength region. ${ }^{17,21,27-30}$ For comparison with the experiment, the calculated vibrational frequencies were convoluted with a Lorentzian line shape with a full width at halfmaximum (fwhm) of $15 \mathrm{~cm}^{-1}$. In two special cases, when the energy difference at the DFT level was very low, we have performed an additional MP2 single point energy evaluation to check the reliability of the theoretical level.

Experimental Details. IRMPD experiments have been performed using a modified quadrupole Paul ion trap (Esquire 3000+, Bruker) coupled to the tunable IR radiation produced by the FEL at the Centre Laser Infrarouge CLIO (Orsay, France). ${ }^{31}$ This facility is based on a $10-44 \mathrm{MeV}$ electron accelerator and provides radiation over the IR wavelength range $3-120 \mu \mathrm{m}$ with a relative bandwidth of $0.5 \%$ (fwhm). 
Table 1. Calculated Relative Energies and 298 K Free Energies (Given in Parentheses) of the CIP Metal Ion Complexes ${ }^{a}$

\begin{tabular}{|c|c|c|c|c|c|c|c|}
\hline isomer & $\mathrm{Li}^{+}$ & $\mathrm{Na}^{+}$ & $\mathrm{K}^{+}$ & $\mathrm{Ag}^{+}$ & $\mathrm{Mg}^{2+}$ & $\mathrm{Mg}^{2+}\left(\mathrm{H}_{2} \mathrm{O}\right)_{3}$ & {$\left[\mathrm{Al}(\mathrm{OH})_{2}\right]^{+}$} \\
\hline SC & $28.30(28.04)$ & $5.57(6.70)$ & $0(1.26)$ & $0(0)$ & $95.12(95.44)$ & $39.48(40.47)$ & $47.52(47.72)$ \\
\hline M & $0(0)$ & $0(0)$ & $0.25(0)$ & $9.80(9.63)$ & 40.07 (40.18) & $8.91(9.04)$ & $0(0)$ \\
\hline $\mathrm{Z2}$ & $175.34(169.52)$ & $172.79(168.27)$ & $180.12(176.22)$ & $148.88(143.57)$ & $88.68(87.06)$ & $47.91(43.32)$ & $137.33(135.20)$ \\
\hline $\mathrm{Z} 1$ & $137.87(135.20)$ & $161.48(159.06)$ & $175.01(173.75)$ & $151.73(148.18)$ & $0(0)$ & $0(0)$ & $79.42(79.11)$ \\
\hline
\end{tabular}

Table 2. Vertical Binding Energies Evaluated through a Counterpoise Procedure at the B3LYP/6-311+G(d,p) Level ${ }^{a}$

$\begin{array}{cccccccc}\text { isomer } & \mathrm{Li}^{+} & \mathrm{Na}^{+} & \mathrm{K}^{+} & \mathrm{Ag}^{+} & \mathrm{Mg}^{2+} & \mathrm{Mg}^{2+}\left(\mathrm{H}_{2} \mathrm{O}\right)_{3} & {\left[\mathrm{Al}(\mathrm{OH})_{2}\right]^{+}} \\ \mathbf{S C} & 396.4 & 305.2 & 243.6 & 360.0 & 1044.8 & 749.4 & 658.0 \\ \mathbf{M} & 410.2 & 299.3 & 234.0 & 337.4 & 1089.6 & 682.4 & 701.2 \\ \mathbf{Z 2} & 566.4 & 457.9 & 385.5 & 529.5 & 1358.4 & 970.1 & 887.9 \\ \mathbf{Z 1} & 603.6 & 470.1 & 393.1 & 535.8 & 1450.9 & 1038.2 & 963.2\end{array}$

${ }^{a}$ All the values are in $\mathrm{kJ} / \mathrm{mol}$.

The IR-FEL beam was mildly focused in the trap using a $400 \mathrm{~mm}$ $\mathrm{ZnSe}$ focal lens and conducted into the vacuum chamber through a diamond window. A conical hole (diameter $=1.2 \mathrm{~mm}$ ) was made in the ring electrode of the trap to allow the optical access to the center of the trap. Multistage mass spectrometry was carried out using the standard Bruker Esquire Control (v5.2) software. Mass-selected ions were irradiated using the MS2 step, where the excitation amplitude was set to zero to avoid any collision-induced dissociation processes. The typical irradiation time was $500 \mathrm{~ms}$, except for complexes with aluminum, where it was $150 \mathrm{~ms}$ to avoid complete fragmentation of the trapped ion. The laser power was around $750 \mathrm{~mW}$ in the $1100-$ $1700 \mathrm{~cm}^{-1}$ range and fell off to about $600 \mathrm{~mW}$ just toward the blue edge of the tuning range. Because the laser power was quite constant in the absorption range for all the metal CIP complexes, no correction was applied to the measured data.

Mass spectra were recorded after 10 accumulations, using the mass range 100-500 amu, and this sequence was repeated two times at each photon energy. The mass spectrum is subject to a low-mass cutoff fixed in all cases to $25 \%$ of the mass ion isolated in the trap.

$\mathrm{CIP}$ and metal salts $\mathrm{LiNO}_{3}, \mathrm{NaCl}, \mathrm{KCl}, \mathrm{Al}(\mathrm{OH})_{3}, \mathrm{AgNO}_{3}$, and $\mathrm{MgSO}_{4}$ were purchased from Sigma-Aldrich and used without further purification. Methanol solutions of ciprofloxacin at $10^{-4} \mathrm{M}$ were prepared and introduced into the source by means of direct infusion with a syringe pump. The ESI conditions used were as follows: flow rate $=150 \mu \mathrm{L} / \mathrm{h}$; spray voltage $=-4500 \mathrm{~V}$; capillary temperature $=$ $423 \mathrm{~K}$.

\section{RESULTS}

Calculated Structures and Energies. Similarly to other amphoteric quinolones, the CIP molecule exists either in zwitterionic $(\mathbf{Z})$ or nonionic molecular $(\mathbf{M})$ form. In the first case, the localization of negative and positive charges in the molecule lead to deprotonation of the carboxylic acid group, with the resulting proton attached on the terminal nitrogen atom in the piperazinyl ring. The presence of the quinolone carbonyl in the $\beta$ position with respect to the carboxylic acid allows the existence of another structure with separated charge (SC), in which the $\mathrm{COOH}$ proton moves on the adjacent carbonyl.

The theoretical investigation on the geometry of the cationic CIP systems considered in this work reveals that there are four relevant structural themes, which are shown in Figure 1, that is, $\mathbf{M}, \mathbf{S C}, \mathbf{Z 1}$, and $\mathbf{Z 2}$. According to the metal ion coordination site, these structures can be classified into two groups: those in which the metal ion coordinates either to the quinolone carbonyl group and one of the oxygen atoms of the carboxylic group ( $\mathbf{M}$ and $\mathbf{Z 1}$ ), and those in which the metal ion coordinates both oxygen atoms of the carboxylic acid group (SC and Z2). All four isomers involve a bidentate chelation pattern.

Table 1 reports the relative energies and relative free energies calculated for the optimized structures of the CIP metal ion isomers (the energy difference includes the zero point energy harmonic correction). BSSE effects have been checked to be very small by explicit computation of the binding energy through counterpoise method (see discussion in Table 2).

As shown in Table 1, in the case of alkali metals, the structures $\mathbf{Z 1}$ and $\mathbf{Z 2}$, in which CIP presents a zwitterionic structure, are calculated to be less stable than $\mathbf{M}$ and SC. The free energy difference between these two groups of structures spans from $107 \mathrm{~kJ} / \mathrm{mol}\left(\mathrm{CIP} \mathrm{Li}{ }^{+}\right)$to $172 \mathrm{~kJ} / \mathrm{mol}\left(\mathrm{CIP} \mathrm{K}{ }^{+}\right)$and increases as the metal cation becomes larger.

In the case of CIP $\mathrm{Li}^{+}, \mathrm{CIP} \mathrm{Na}{ }^{+}$, and CIP $\mathrm{K}^{+}, \mathbf{M}$ is calculated to have the lower free energy. For CIP $\mathrm{Ag}^{+}$, the most stable calculated structure is SC. In the case of CIP $\mathrm{Na}^{+}$and CIP K${ }^{+}$, the energy differences between the $\mathbf{M}$ and $\mathbf{S C}$ structures were of a few kilojoules per mole (see Table 1). Thus, these energies were also recalculated at the single point MP2 level at the DFToptimized structure. It was found that the $\mathbf{M}$ isomer is the most stable for both the complexes and the SC isomer is higher in energy of $2.30 \mathrm{~kJ} / \mathrm{mol}$ in the case of CIP $\mathrm{Na}^{+}$and $3.10 \mathrm{~kJ} / \mathrm{mol}$ in the case of CIP $\mathrm{K}^{+}$.

Complexes of CIP with polyvalent $\mathrm{Al}^{3+}$ and $\mathrm{Mg}^{2+}$ metal cations were also investigated. In the case of aluminum, the CIP $\left[\mathrm{Al}(\mathrm{OH})_{2}\right]^{+}$complex was taken into account as the ESI mass spectrum revealed that only this adduct was produced. Theoretical investigations on this complex pointed out the $\mathbf{M}$ structure as the most stable one, with the two $\mathrm{OH}^{-}$groups bonded to the cation, which results in a quasi-tetrahedral configuration. For what concerns complexes with magnesium, both CIP $\mathrm{Mg}^{2+}$ and CIP $\mathrm{Mg}^{2+}\left(\mathrm{H}_{2} \mathrm{O}\right)_{3}$ complexes were taken into account in Table 1 , as hydration occurs in the mass spectrometer (see the IRMPD Spectra section). These adducts show a common trend in the stability order of the different isomers: both of them are predicted to prefer the zwitterionic form Z1, with hydration providing a minor stabilization of this isomer with respect to the second more stable one, $\mathbf{M}$. The $\mathbf{Z 1}$ structure of CIP $\mathrm{Mg}^{2+}\left(\mathrm{H}_{2} \mathrm{O}\right)_{3}$ presents a trigonal bipyramidal molecular geometry around the metal cation: the quinolone carbonyl group and one oxygen atom of the water molecules occupy the apexes of the bipyramid, whereas the oxygen atom of the CIP carboxylic group and the other two oxygen atoms of 
the water molecules occupy the corners. We must point out that the magnesium ion is the only effectively polyvalent metal ion, since $\mathrm{Al}^{3+}$ really comes in a monocationic form due to the $\mathrm{OH}$ complexation. In the case of $\mathrm{Mg}^{2+}$ and $\mathrm{Mg}^{2+}\left(\mathrm{H}_{2} \mathrm{O}\right)_{3}$, the strong increase in the density of positive charge in the $\mathbf{M}$ structures leads to a preferential stabilization of the zwitterionic moiety where the positive charge turns out less congested on one end of the molecule.

In Table 2, we report the vertical binding energies between the metal (or metal complex in the cases of $\left[\mathrm{Al}(\mathrm{OH})_{2}\right]^{+}$and $\left.\mathrm{Mg}^{2+}\left(\mathrm{H}_{2} \mathrm{O}\right)_{3}\right)$ and ciprofloxacin calculated through a counterpoise procedure. ${ }^{32}$ The counterpoise procedure has also allowed us to trace the BSSE error made in evaluating the energies that is slightly below $1 \%$ of the binding energy and therefore unlikely to affect the overall geometric optimization. The binding energy is always greater for the zwitterionic species but not enough to counterbalance the energetic loss due to the charge separation, ${ }^{23}$ except in the cases of $\mathrm{Mg}^{2+}$ and $\mathrm{Mg}^{2+}\left(\mathrm{H}_{2} \mathrm{O}\right)_{3}$, where the binding energy differences between neutral and zwitterions are the highest.

IRMPD Spectra. The analysis of the IRMPD mass spectra of CIP complexes with $\mathrm{Li}^{+}, \mathrm{Na}^{+}, \mathrm{K}^{+}, \mathrm{Ag}^{+},\left[\mathrm{Al}(\mathrm{OH})_{2}\right]^{+}$, and $\mathrm{Mg}^{2+}\left(\mathrm{H}_{2} \mathrm{O}\right)_{3}$ reveals different behaviors.

For the CIP complexes with alkali metal ions, the signals of the precursor clusters predominate in the mass spectra. In the case of the CIP $\mathrm{Li}^{+}$complex, a minor feature attributable to the dehydrated CIP molecule can be observed, whereas in the spectra of CIP $\mathrm{Na}^{+}$and CIP $\mathrm{K}^{+}$very low signals attributable to the loss of water and $\mathrm{CO}_{2}$ are present but their intensities are under the threshold of 5\%. These results are consistent with collision-induced dissociation (CID) experiments. The absence of intense fragmentation signals in IRMPD mass spectra of these complexes may be attributed to the fact that the photodissociation processes mainly result in the loss of the intact ligand leaving the bare metal cations $\left(\mathrm{Li}^{+}, \mathrm{Na}^{+}, \mathrm{K}^{+}\right)$, which cannot be detected due to the cutoff of the ion trap.

In the case of CIP $\mathrm{Ag}^{+}$, a large number of features are present in the IRMPD mass spectrum, including ion signals corresponding to the loss of $\mathrm{H}_{2} \mathrm{O}$ and $\mathrm{CO}_{2}$. Additional peaks can be assigned to fragments of the bare CIP molecule. A similar fragmentation pattern has been observed in the CID mass spectrum of the CIP $\mathrm{Ag}^{+}$complex.

In the ESI mass spectrum of the solution containing CIP and aluminum cation, no evidence of the production of the CIP $\mathrm{Al}^{3+}$ complex was found. However, an ion signal at $\mathrm{m} / z$ 392, corresponding to the $\mathrm{CIP}\left[\mathrm{Al}(\mathrm{OH})_{2}\right]^{+}$complex, was observed and isolated in the trap. The production of this complex has been already reported in the literature. ${ }^{33}$ Both the CID and the IRMPD mass spectra of the $\mathrm{CIP}\left[\mathrm{Al}(\mathrm{OH})_{2}\right]^{+}$complex present only one product at $m / z 332$ that could be attributed to $\mathrm{CIPH}^{+}$, resulting from the loss of neutral $\mathrm{AlO}_{2} \mathrm{H}$.

For what concerns alkaline earth cations, $\mathrm{Mg}^{2+}$ and $\mathrm{Ca}^{2+}$ were taken into account. For the $\mathrm{Mg}^{2+}$ complex, the strong affinity of this metal with water leads to multiple hydration of the CIP $\mathrm{Mg}^{2+}$ complex both in the ESI process and in the trap. The analysis of the photodissociation spectra points out that the complex CIP $\mathrm{Mg}^{2+}\left(\mathrm{H}_{2} \mathrm{O}\right)_{3}$ is the precursor ion. The IRMPD mass spectrum presents the ion signal of the parent at $m / z 205$ and a number of fragments at $\mathrm{m} / z 196,183$, and 173 corresponding to the loss of $\mathrm{H}_{2} \mathrm{O}, \mathrm{CO}_{2}$, and $\mathrm{CO}_{2}+\mathrm{HF}$, respectively. We did not observe the formation of the CIP Ca ${ }^{2+}$ complex.
The ion abundances in the mass spectra recorded at each wavenumber allowed the calculation of the IRMPD efficiency, $R=-\ln \left(I_{\text {parent }} /\left(I_{\text {parent }}+\sum I_{\text {fragment }}\right)\right)$, where $I_{\text {parent }}$ and $I_{\text {fragment }}$ are the parent and fragment ion intensities, respectively., 18,34 Figure 2 reports the IRMPD spectra of complexed CIP in the

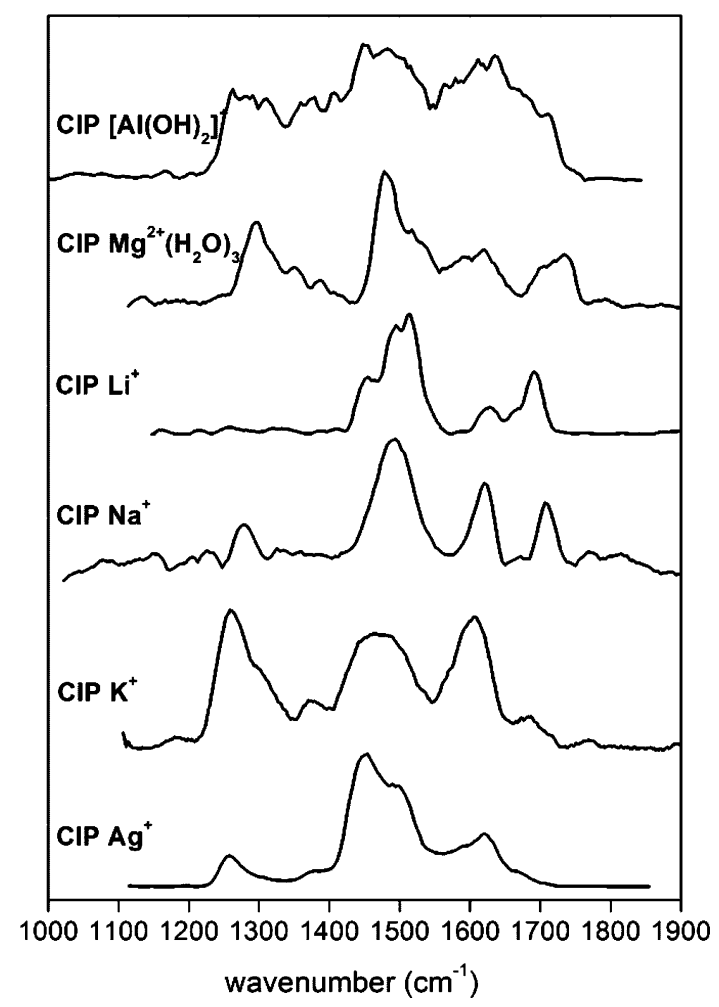

Figure 2. IRMPD spectra of the investigated CIP metal complexes in the $1000-1900 \mathrm{~cm}^{-1}$ range.

1000-1900 $\mathrm{cm}^{-1}$ range. For the complexes with $\mathrm{Li}^{+}, \mathrm{Ag}^{+}$, $\left[\mathrm{Al}(\mathrm{OH})_{2}\right]^{+}$, and $\mathrm{Mg}^{2+}\left(\mathrm{H}_{2} \mathrm{O}\right)_{3}$, the IRMPD spectra represent the plot of $R$ factor versus the photon energy. As the intensities of the fragments of the CIP $\mathrm{Na}^{+}$and CIP $\mathrm{K}^{+}$were negligible (see previous discussion on the mass spectra), Figure 2 reports the inverse of the depletion spectra of the parent ions for these complexes.

All the IRMPD spectra present a common intense absorption in the $1400-1550 \mathrm{~cm}^{-1}$ region, which is characteristic of aromatic $\mathrm{C}-\mathrm{C}$ stretching and $\mathrm{CH}_{2}$ twisting/rocking modes of these systems, and one in the range $1550-1650 \mathrm{~cm}^{-1}$, characteristic of aromatic $\mathrm{C}-\mathrm{C}$ stretching. A feature in the range $1250-1350 \mathrm{~cm}^{-1}$, which is typical of $\mathrm{CH}_{2}$ twisting and rocking modes, can also be observed in each spectrum, except for the CIP $\mathrm{Li}^{+}$. In this case, some bands may be not accounted by the $R$ factor, as the only detected fragment was very low and probably the photodissociation of the precursor ion mainly results in the production of the $\mathrm{Li}^{+}$ion, which cannot be detected as already described. ${ }^{35}$

For the complexes of $\mathrm{Li}^{+}, \mathrm{Na}^{+}$, and $\mathrm{Mg}^{2+}\left(\mathrm{H}_{2} \mathrm{O}\right)_{3}$, an absorption around $1700 \mathrm{~cm}^{-1}$ is detected, which is less distinct for CIP $\left[\mathrm{Al}(\mathrm{OH})_{2}\right]^{+}$and CIP $\mathrm{K}^{+}$and absent in the spectrum of CIP $\mathrm{Ag}^{+}$. This observation suggests that the metal ions differently coordinate the CIP molecule leading to different isomers. 


\section{DISCUSSION}

The relative intensities of the calculated absorption frequencies of the various isomers may not reflect the relative intensities of the IRMPD peaks because the latter come from multiple photon processes, whereas the theoretical IR spectra are based on single photon absorption. It should be considered that the intensities of the experimental IRMPD signals are determined by the probability of depositing enough excess energy into the specific bonds involved in the complex fragmentation. This does not depend only on the efficiency of resonant photon absorption but also on the efficiency of intermolecular vibrational relaxation processes. ${ }^{36}$

The nonlinear absorption nature of multiple photon absorption in the IRMPD processes may also cause red shifts and broadening of the transitions due to anharmonic vibrational couplings. ${ }^{15,37}$ Depending on the vibrational mode of the molecular ion, this red shift typically varies between 10 and $30 \mathrm{~cm}^{-1}$ and can often be absorbed in the scaling factor. However, for heavily affected modes, this red shift may not be fully compensated for by the scaling factor. ${ }^{38}$

It is worthwhile to consider that skeletal modes in the region $1200-1700 \mathrm{~cm}^{-1}$, as $\mathrm{CH}$ in-plane bending and $\mathrm{C}-\mathrm{C}$ stretching modes, appear to be generally broader than those in other wavelength ranges, such as the $\mathrm{CH}$ out-of-plane bending modes in the $500-800 \mathrm{~cm}^{-1}$ region. ${ }^{37}$ In some cases, this broadening could be due to a convolution over several unresolved bands, but generally, it may be explained by assuming that these modes show larger anharmonicity, as found for a number of polycyclic aromatic hydrocarbons. ${ }^{37,39,40}$

A further side effect of anharmonic coupling is that IRMPD intensities for two close-lying transitions are modified such that the lower-frequency mode gains intensity. ${ }^{15,37}$

Quinolone and Carboxylic Carbonyls Coordination: $\mathrm{Li}^{+}, \mathrm{Na}^{+},\left[\mathrm{Al}(\mathrm{OH})_{2}\right]^{+}$, and $\mathrm{Mg}^{2+}\left(\mathrm{H}_{2} \mathrm{O}\right)_{3}$. Figure 3 displays the calculated spectra of the four isomers $\mathbf{M}, \mathbf{S C}, \mathbf{Z 1}$, and $\mathbf{Z 2}$ of CIP $\mathrm{Na}^{+}$compared with the IRMPD spectrum (red line) measured for this complex.

The $\mathbf{M}$ isomer, calculated to be the most stable one, provides a good match to the experimental spectrum, apart from the low frequency region. The SC structure, about $7 \mathrm{~kJ} / \mathrm{mol}$ higher in energy than the $\mathbf{M}$ one, shows a worse agreement with the experimental spectrum; in particular, it does not show any signal in the diagnostic $1700 \mathrm{~cm}^{-1}$ region. The zwitterionic structures can be ruled out on the basis of both spectroscopic and energetically considerations (see Figure 3 and Table 1). We have considered different combinations of the conformers to find an optimal match of the predicted spectrum with the experimental one. The attempts produced only a general worsening of the agreement when the zwitterionic structures were taken into account. Although energetic considerations would lead to a mixture of $\mathbf{M}$ and SC states, it seems that the experiments point prevalently to the $\mathbf{M}$ species. Increasing the SC percentage up to more than $20 \%$ with respect to the $\mathbf{M}$ conformer leads to a worsening of the match of the experimental and calculated spectra in the high frequency region without a significative improvement in the low frequency range.

From this evidence, the CIP $\mathrm{Na}^{+}$complex appears to have the $\mathbf{M}$ geometry, with the sodium cation coordinating both of the carbonyl groups. Accordingly, the vibrational features in the IRMPD spectrum can be assigned. The band observed at 1708 $\mathrm{cm}^{-1}$ corresponds to the $\mathrm{C}=\mathrm{O}$ stretching of the carboxylic

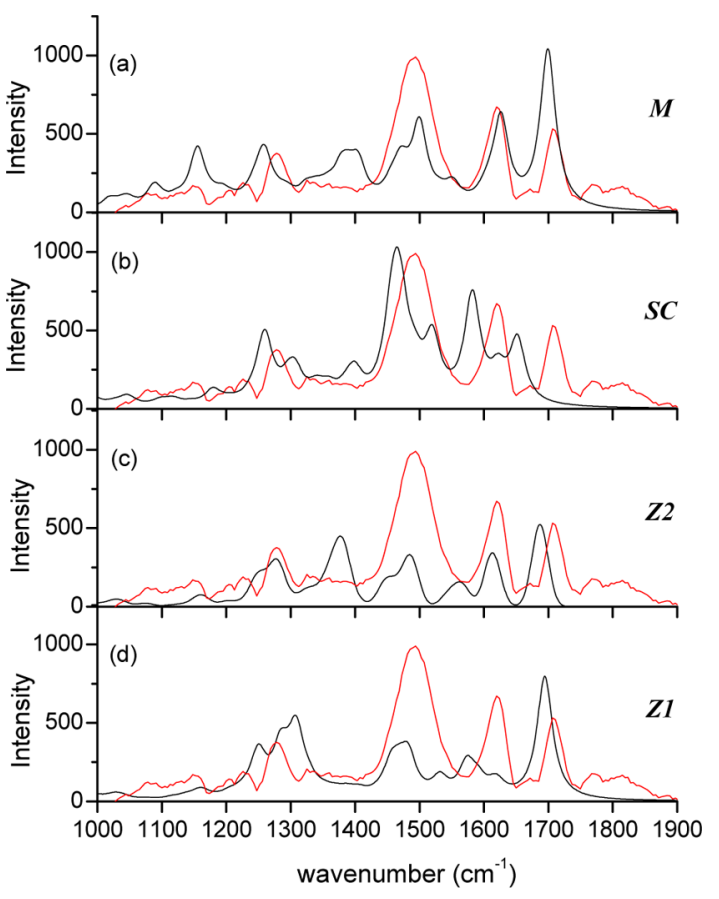

Figure 3. Calculated spectra (black) of the different isomers (a) $\mathbf{M}$, (b) SC, (c) Z2, and (d) Z1 of the CIP $\mathrm{Na}^{+}$complex, plotted as Lorentzian convolution (fwhm of $15 \mathrm{~cm}^{-1}$ ) of theoretical IR stick spectra. The IRMPD experimental spectrum is overlaid in red.

group. The predicted band for the $\mathbf{M}$ isomer is at $1699 \mathrm{~cm}^{-1}$. This band in the isolated ciprofloxacin molecule was found at $1762 \mathrm{~cm}^{-1}$, 23 indicating that the interaction with the sodium cation causes an expected red shift of the $\mathrm{C}=\mathrm{O}$ stretching frequency. The band at $1620 \mathrm{~cm}^{-1}$ fits very well with the calculated one at $1626 \mathrm{~cm}^{-1}$, corresponding to $\mathrm{C}-\mathrm{C}$ aromatic stretching. Different vibrational modes contribute to the broad feature centered at $1490 \mathrm{~cm}^{-1}: \mathrm{CH}_{2}$ scissoring (calculated at $\left.1470 \mathrm{~cm}^{-1}\right), \mathrm{C}-\mathrm{C}$ aromatic stretching and $\mathrm{C}-\mathrm{N}$ stretching of the piperazinyl ring (predicted at $1499 \mathrm{~cm}^{-1}$ ), and quinolone $\mathrm{C}=\mathrm{O}$ stretching (predicted at $1549 \mathrm{~cm}^{-1}$ ). Also, in this latter case, the interaction with the $\mathrm{Na}^{+}$ion results in a red shift of the $\mathrm{C}=\mathrm{O}$ stretching with respect to the free $\mathrm{CIPH}^{+}{ }^{23}$ The band at $1278 \mathrm{~cm}^{-1}$ has the largest deviation $\left(20 \mathrm{~cm}^{-1}\right)$ with the calculated one at $1258 \mathrm{~cm}^{-1}$, corresponding to $\mathrm{CH}_{2}$ twisting modes. The $\mathrm{C}-\mathrm{O}-\mathrm{H}$ bending mode predicted at $1154 \mathrm{~cm}^{-1}$ is found experimentally at $1152 \mathrm{~cm}^{-1}$ but with a lower intensity.

The calculated IR spectrum of the $\mathbf{M}$ isomer also predicts a band around $1390 \mathrm{~cm}^{-1}$ that is not clearly detected in the experimental spectrum. This absorption comes from a large number of predicted low intensities modes, that is, $\mathrm{CH}_{2}$ scissoring and twisting modes, $\mathrm{C}-\mathrm{O}-\mathrm{H}$ bending, and mixed skeletal vibrations, which coalesce when the spectrum is plotted as Lorentzian convolution and produce a large band in the $1360-1420 \mathrm{~cm}^{-1}$ region, where the experimental spectrum shows nonzero absorptions.

The IRMPD spectra of complexes CIP $\mathrm{Li}^{+}$and CIP $\left[\mathrm{Al}(\mathrm{OH})_{2}\right]^{+}$are reported in the Supporting Information. The comparison with the simulated spectra for the four possible structures of these complexes would suggest to assign the $\mathbf{M}$ structure to CIP $\mathrm{Li}^{+}$, whereas it does not provide a convincing spectroscopic argument for structural assignment of CIP $\left[\mathrm{Al}(\mathrm{OH})_{2}\right]^{+}$, which presents a very unresolved IRMPD spectrum due probably to the joint contribution from different 
isomers. Pure energetic considerations allow the correlation of both these clusters to the $\mathbf{M}$ structure, which is calculated to be the more stable one. In fact, the second more stable isomer, SC, results to be $\sim 28 \mathrm{~kJ} / \mathrm{mol}$ for $\mathrm{Li}^{+}$and $48 \mathrm{~kJ} / \mathrm{mol}$ for $\left[\mathrm{Al}(\mathrm{OH})_{2}\right]^{+}$ higher in free energy than $\mathbf{M}$, and the gap with the zwitterionic structures is more than $80 \mathrm{~kJ} / \mathrm{mol}$.

Figure $4 a-d$ reports the calculated IR spectra for the four structures $\mathbf{M}, \mathbf{S C}, \mathbf{Z 1}$, and $\mathbf{Z 2}$ predicted for the CIP

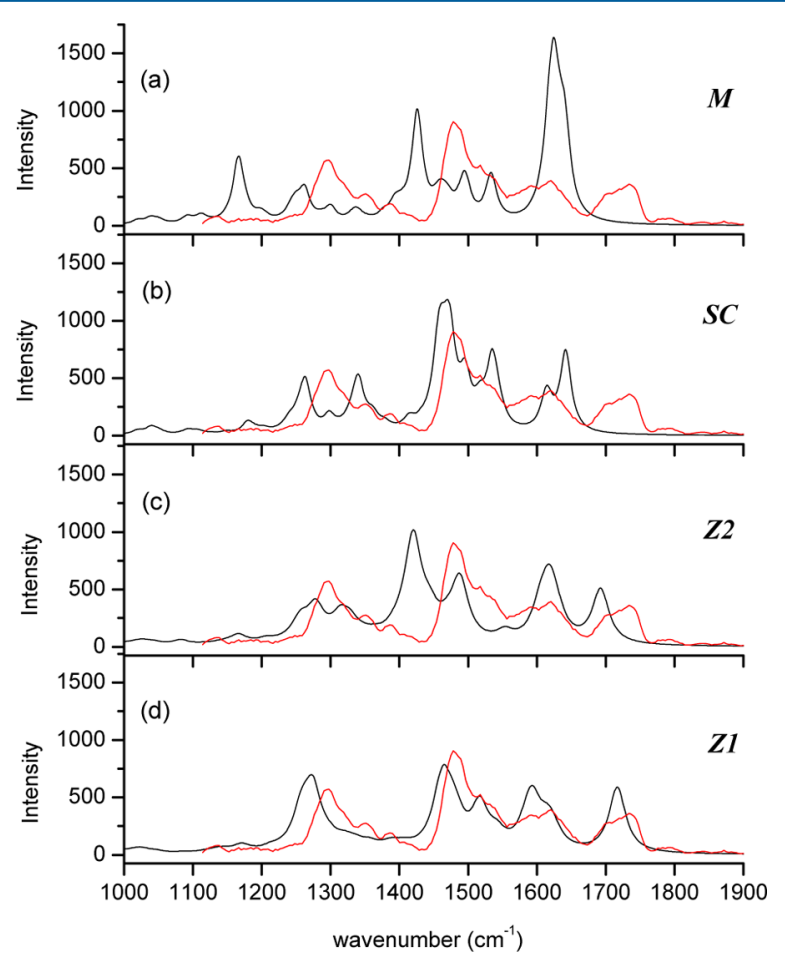

Figure 4. Calculated spectra (black line) of the different isomers (a) M, (b) SC, (c) Z2, and (d) $\mathbf{Z 1}$ of the CIP $\mathrm{Mg}^{2+}\left(\mathrm{H}_{2} \mathrm{O}\right)_{3}$ complex, plotted as Lorentzian convolution (fwhm of $15 \mathrm{~cm}^{-1}$ ) of theoretical IR stick spectra. The IRMPD experimental spectrum is overlaid in red.

$\mathrm{Mg}^{2+}\left(\mathrm{H}_{2} \mathrm{O}\right)_{3}$ complex. The $\mathbf{Z 1}$ structure is energetically favored and displays the better match with the experimental IRMPD spectrum of CIP $\mathrm{Mg}^{2+}\left(\mathrm{H}_{2} \mathrm{O}\right)_{3}$.

According to this assignment, we can interpret the vibrational features. The band centered at $1720 \mathrm{~cm}^{-1}$ can be assigned to the carboxylate $\mathrm{C}=\mathrm{O}$ stretching, predicted at $1716 \mathrm{~cm}^{-1}$. Aromatic $\mathrm{C}-\mathrm{C}$ stretching, $\mathrm{NH}_{2}^{+}$scissoring, and $\mathrm{H}_{2} \mathrm{O}$ bending contribute to the large feature at $\sim 1620 \mathrm{~cm}^{-1}$ (predicted at $1616 \mathrm{~cm}^{-1}$ ), and the small band at $1592 \mathrm{~cm}^{-1}$ matches perfectly with the predicted one for $\mathrm{H}_{2} \mathrm{O}$ bending. The shoulder at 1520 $\mathrm{cm}^{-1}$ corresponds both to aromatic $\mathrm{C}-\mathrm{C}$ and quinolone $\mathrm{C}=$ $\mathrm{O}$ stretching, whereas the large band at $1478 \mathrm{~cm}^{-1}$ can be assigned to the in-plane bending of the aromatic $\mathrm{CH}$ and to $\mathrm{CH}_{2}$ scissoring modes (predicted at $1465 \mathrm{~cm}^{-1}$ ). The region $1330-1400 \mathrm{~cm}^{-1}$ is characterized by $\mathrm{CH}_{2}$ twisting and rocking motions and $\mathrm{C}-\mathrm{N}$ stretching of the piperazinyl ring. The intense band centered at $\sim 1295 \mathrm{~cm}^{-1}$ is attributed to both carboxylic $\mathrm{CO}^{-}$stretching and mixed skeleton motions (predicted at $1276 \mathrm{~cm}^{-1}$ ).

Carboxylate Group Coordination: $\mathrm{K}^{+}$and $\mathrm{Ag}^{+}$. The experimental IRMPD spectra of CIP $\mathrm{K}^{+}$and CIP $\mathrm{Ag}^{+}$clearly show a similar pattern (see Figure 2), apart for the relative intensities of the signals. Furthermore, no intense features are observed in the region around $1700 \mathrm{~cm}^{-1}$ at variance with the spectra of the other metal complexes. These findings suggest that $\mathrm{CIP} \mathrm{K}^{+}$and CIP $\mathrm{Ag}^{+}$could be assigned to the same type of structure.

The predicted IR spectra for the four isomers of CIP $\mathrm{K}^{+}$ complex are reported in Figure $5 \mathrm{a}-\mathrm{d}$.

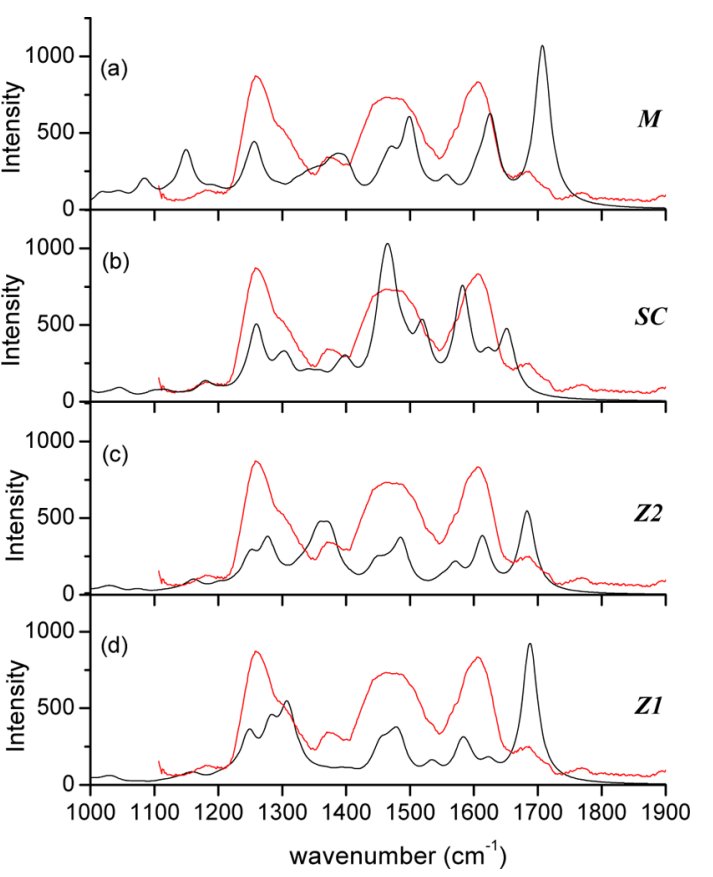

Figure 5. Calculated spectra (black) of the different isomers (a) $\mathbf{M}$, (b) SC, (c) $\mathbf{Z 2}$, and (d) $\mathbf{Z 1}$ of the CIP $\mathrm{K}^{+}$complex, plotted as Lorentzian convolution ( $\mathrm{fwhm}$ of $15 \mathrm{~cm}^{-1}$ ) of theoretical IR stick spectra. The IRMPD experimental spectrum is overlaid in red.

The zwitterionic structures $\mathbf{Z 1}$ and $\mathbf{Z 2}$ present a strong absorption at approximately $1700 \mathrm{~cm}^{-1}$ that is not detected in the experimental spectrum. The $\mathbf{M}$ structure is the most stable at the MP2 level, but there is little evidence in the spectrum of significant contribution from this isomer, as revealed by the lack of the diagnostic carboxylic $\mathrm{C}=\mathrm{O}$ stretching at approximately $1700 \mathrm{~cm}^{-1}$. The SC isomer is energetically feasible and provides a good match to the experimental spectrum (see Figure $5 \mathrm{~b}$ ) apart from the range $1550-1650 \mathrm{~cm}^{-1}$, where a broad absorption is found instead of two predicted diagnostic vibrations. Despite the presence of the other structures to the extent of a few percent cannot be excluded, the combination of the SC conformer with significant contribution from the $\mathbf{M}, \mathbf{Z 1}$, or $\mathbf{Z 2}$ structures did not produce a better match with the experimental IRMPD spectrum.

Following the assignment to the SC structure, we may identify the vibrational features present in the depletion spectrum of CIP $\mathrm{K}^{+}$. The high frequency region of the experimental spectrum is characterized by a large band centered at $\sim 1608 \mathrm{~cm}^{-1}$, whereas the IR spectrum of the SC isomer present different vibrational modes: the $\mathrm{C}-\mathrm{O}-\mathrm{H}$ bending and the $\mathrm{CO}_{2}^{-}$asymmetric stretching both predicted at 1651 and $1582 \mathrm{~cm}^{-1}$; and the $\mathrm{C}-\mathrm{C}$ aromatic stretching predicted at 1622 and $1582 \mathrm{~cm}^{-1}$. The discrepancy between the experimental and theoretical spectra can be attributed to strong anharmonic effects that cause broadenings on both the $\mathrm{C}-\mathrm{C}$ aromatic stretching (already discussed in previous section) and the $\mathrm{C}-$ $\mathrm{O}-\mathrm{H}$ bending. In particular, the latter vibration is perturbed by the strong intramolecular hydrogen bond predicted for the SC 
structure. As reported in the literature, species with a proton shared between two neutral or negatively charged heteroatoms $^{38,41,42}$ present broad spectral resonances for the absorption involving the $\mathrm{O} \cdots \mathrm{H}^{+} \cdots \mathrm{O}$ moiety.

The band centered at $1470 \mathrm{~cm}^{-1}$ can be attributed to $\mathrm{C}-\mathrm{C}$ aromatic stretching (calculated at $1519 \mathrm{~cm}^{-1}$ ) and to $\mathrm{CH}_{2}$ twisting and scissoring modes (calculated at $1465 \mathrm{~cm}^{-1}$ ). The small feature at $1375 \mathrm{~cm}^{-1}$ is assigned to mixed skeleton modes and $\mathrm{C}-\mathrm{N}$ stretching of the piperazinyl ring and is quite red shifted with respect to the calculated value $\left(1398 \mathrm{~cm}^{-1}\right)$. The band at $1260 \mathrm{~cm}^{-1}$ and the shoulder at $1297 \mathrm{~cm}^{-1}$ fit very well with the $\mathrm{CH}_{2}$ rocking modes predicted at 1260 and $1302 \mathrm{~cm}^{-1}$. These intense absorptions preclude the clear observation of the $\mathrm{CO}_{2}^{-}$symmetric stretching, which is predicted at $1301 \mathrm{~cm}^{-1}$.

Analogous considerations can be applied in the comparison of the IRMPD spectrum of CIP $\mathrm{Ag}^{+}$with the calculated IR spectra of the possible isomers. The zwitterionic structures can be excluded as they show a very different spectroscopic profile (see the Supporting Information) and are too high in energy $(\sim 150 \mathrm{~kJ} / \mathrm{mol})$. The $\mathbf{M}$ structure is about $10 \mathrm{~kJ} / \mathrm{mol}$ less stable than the SC one, and its predicted IR spectrum does not match with the experimental IRMPD spectrum both in the low frequency region and in the diagnostic region at $1700 \mathrm{~cm}^{-1}$.

As for CIP $\mathrm{K}^{+}$, the main concern of the assignment to the SC structure is the discrepancy between the experimental and calculated spectra in the high frequency region. In fact, the experimental spectrum is characterized by a broad band around $1600 \mathrm{~cm}^{-1}$, whereas the IR spectrum of the SC isomer predicts the $\mathrm{C}-\mathrm{O}-\mathrm{H}$ bending and the $\mathrm{CO}_{2}^{-}$asymmetric stretching both calculated at 1642 and $1568 \mathrm{~cm}^{-1}$ and the $\mathrm{C}-\mathrm{C}$ aromatic stretching calculated at $1642 \mathrm{~cm}^{-1}$. As described for CIP K $\mathrm{K}^{+}$, the $\mathrm{C}-\mathrm{O}-\mathrm{H}$ bending motions in the SC structure are an example of an H-bridged configuration that is well known to match poorly with harmonic calculation predictions.

Effect of Metal Ion on the Coordination. Spectroscopic and potentiometric studies on the behavior of quinolones and their metal complexes in solution ${ }^{33,43-45}$ refer essentially to divalent metal ions, pointing out that the metal cations are generally coordinated to the quinolone carbonyl and the carboxylate group. Quinolones bearing the piperazinyl ring, as ciprofloxacin, can also involve the terminal nitrogen in the stabilization of the metal complex.

In our previous work on $\mathrm{CIPH}^{+},{ }^{23}$ we found that the isomer observed in the gas phase resulted from the protonation of zwitterionic CIP in the ESI process. Upon protonation, the negative electrical charge of the carboxylate group is neutralized, and the resulting cation retains the protonation at the piperazinyl amino group.

The IRMPD and theoretical investigations reported in this work indicate that different binding motifs to the CIP molecule are found in the gas phase for the different metal ions. Small, strongly binding metal ions act as a sort of chelate ligand and are found to coordinate CIP between the two carbonyl oxygens (quinolone and carboxylic). Figure 6 reports the structural parameters of the CIP metal complexes in the assigned geometry.

The distance between the metal ion and the coordinated CIP oxygen atoms is less than $2 \AA$ in the case of $\mathrm{Li}^{+}, \mathrm{Mg}^{2+}\left(\mathrm{H}_{2} \mathrm{O}\right)_{3}$, and $\left[\mathrm{Al}(\mathrm{OH})_{2}\right]^{+}$, which have short ionic radii, and increases up 2.16 and $2.21 \AA$ in the case of $\mathrm{Na}^{+}$(see Figure 6). Accordingly, the $\mathrm{C}=\mathrm{O}$ bond length in these complexes is larger than the standard value (ca. 1.21 $\AA$ ) and raises up to $1.28 \AA$ in the case of the strongly coordinated CIP $\mathrm{Mg}^{2+}\left(\mathrm{H}_{2} \mathrm{O}\right)_{3}$ and CIP
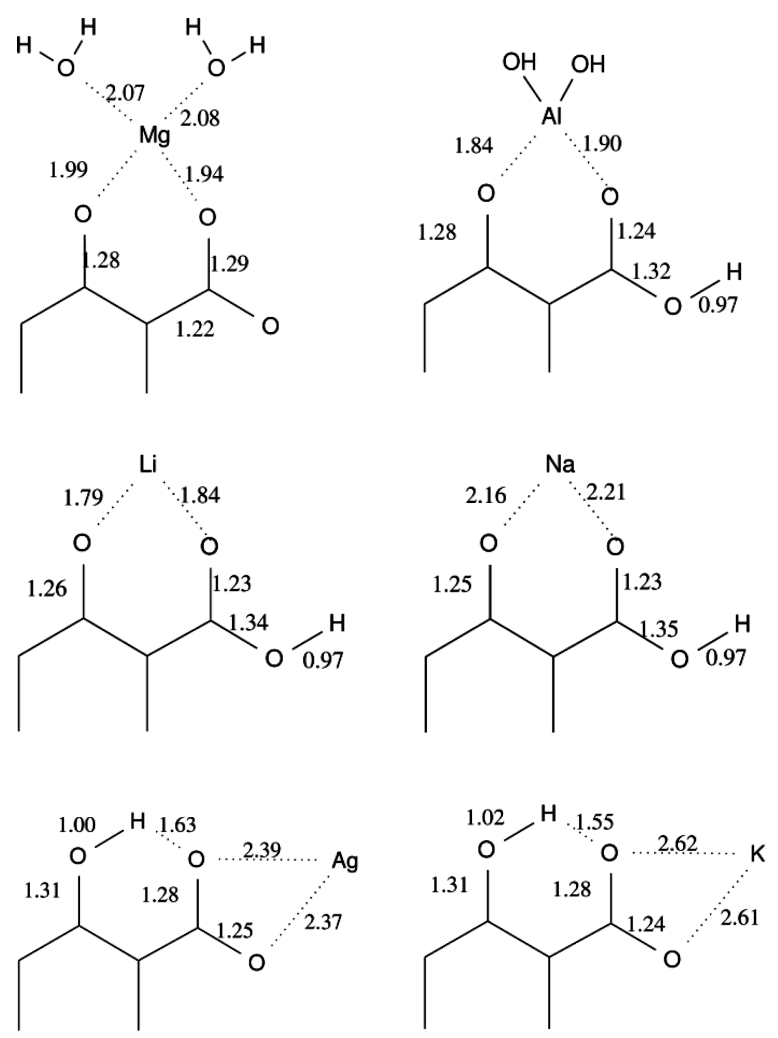

Figure 6. Interatomic distances $(\AA)$ for the coordination site of the CIP complexes with $\mathrm{Mg}^{2+}\left(\mathrm{H}_{2} \mathrm{O}\right)_{3}, \mathrm{Al}(\mathrm{OH})_{2}{ }^{+}, \mathrm{Li}^{+}, \mathrm{Na}^{+}, \mathrm{Ag}^{+}$, and $\mathrm{K}^{+}$ ions. Each complex is considered in the assigned geometry as described in the Discussion sections. In the case of the CIP $\mathrm{Mg}^{2+}\left(\mathrm{H}_{2} \mathrm{O}\right)_{3}$ complex, one of the three water molecules is not drawn for clarity $\left(\mathrm{Mg} \cdots \mathrm{O}_{\text {water }}\right.$ distance $\left.=2.07\right)$.

$\left[\mathrm{Al}(\mathrm{OH})_{2}\right]^{+}$complexes. These structural parameters confirm the higher vertical binding energies calculated for these complexes (see Table 2). The strong interaction of CIP with magnesium and aluminum cations may be related with the inhibition of ciprofloxacin absorption in the intestines when the drug is administered with metallic antacid containing aluminum hydroxide and magnesium oxide. ${ }^{33}$

Larger metal ions, such as $\mathrm{Ag}^{+}$and $\mathrm{K}^{+}$, are found to coordinate the two oxygen atoms of the carboxylate group $\mathrm{CO}_{2}{ }^{-}$. The resulting proton is attached on the adjacent quinolone carbonyl, leading to an intramolecular hydrogen bond (see Figure 6). Large $\mathrm{K}^{+}$and $\mathrm{Ag}^{+}$ions with diffuse, low charge density have weaker ligand binding energies: the distance between the metal ion and the coordinated CIP oxygen atoms range from 2.37 and $2.39 \AA$ in the case of $\mathrm{Ag}^{+}$to 2.61 and $2.62 \AA$ in the case of $\mathrm{K}^{+}$. The formation of an intramolecular hydrogen bond becomes increasingly favored relative to metal ion solvation, resulting in a change in metal ion coordination with increasing metal ion size.

Another interesting aspect is the effect of metal ion size and charge on zwitterion stability. The present study suggests that increasing the metal ion charge has a stabilizing effect on the zwitterionic form as demonstrated by the CIP $\mathrm{Mg}^{2+}\left(\mathrm{H}_{2} \mathrm{O}\right)_{3}$ complex, which is found in the $\mathrm{Z1}$ structure. The zwitterionic structure of CIP $\mathrm{Mg}^{2+}\left(\mathrm{H}_{2} \mathrm{O}\right)_{3}$ is protonated at the terminal nitrogen atom of the piperazinyl ring.

The IRMPD investigation of the electrosprayed methanol solution of CIP and monovalent metal ions does not reveal the presence of the $\mathbf{Z 1}$ and $\mathbf{Z 2}$ structures. This seems in contrast 
Table 3. Experimental and Calculated Values $\left(\mathrm{cm}^{-1}\right)$ of the Carboxylic and Quinolone Carbonyl Stretching for CIPH and CIP Complexes with $\mathrm{Li}^{+}, \mathrm{Na}^{+}$, and $\mathrm{Mg}^{2+}\left(\mathrm{H}_{2} \mathrm{O}\right)_{3}$

\begin{tabular}{|c|c|c|c|c|c|c|c|c|}
\hline & \multicolumn{2}{|c|}{$\mathrm{CIPH}^{+a}$} & \multicolumn{2}{|c|}{ CIP $\mathrm{Li}^{+}$} & \multicolumn{2}{|c|}{ CIP $\mathrm{Na}^{+}$} & \multicolumn{2}{|c|}{ CIP $\mathrm{Mg}^{2+}\left(\mathrm{H}_{2} \mathrm{O}\right)_{3}$} \\
\hline & exptl & calcd & exptl & calcd $^{b}$ & exptl & calcd $^{b}$ & exptl & calcd $^{c}$ \\
\hline$\nu \mathrm{CO}_{\text {carboxylic }}$ & 1762 & 1771 & 1691 & 1681 & 1708 & 1699 & 1716 & 1716 \\
\hline$\nu \mathrm{CO}_{\text {quinolone }}$ & 1620 & 1637 & 1514 & 1523 & & 1549 & 1520 & 1516 \\
\hline
\end{tabular}

${ }^{a}$ Values from ref 23. The experimental value for $\nu \mathrm{CO}_{\text {quinolone }}$ is taken at the center of a large band corresponding also to other vibrational modes. ${ }^{b}$ The values refer to the assigned structure, $\mathbf{M}$ (see the Discussion section). ${ }^{c}$ The values refer to the assigned structure, $\mathbf{Z 1}$ (see the Discussion section).

with what we observed in our previous study on isolated $\mathrm{CIP},{ }^{23}$ where the zwitterionic form was the only one detected. This observation can be explained considering the different role played by the polar solvent on the isolated or complexed CIP. As previously discussed, the solvent effect is that of favoring the presence of CIP zwitterions in the solution, and this probably means that its monocationic metal complexes dissociate in polar solvents. Moreover, CIP in its neutral form is a bidentate chelant, able to form strong complexes with cations in solution, which are brought in the gas phase during the electrospray process. In other words, in the solution of the metal complexes, there is an almost complete dissociation of the $\mathbf{Z 1}$ and $\mathbf{Z 2}$ complexes compared to the $\mathbf{M}$ and SC forms that probably remain bound and therefore the only amenable of being detected. In the case of divalent metal ions, that is, $\mathrm{Mg}^{2+}$, we see that the strong binding energy and presumably the intrinsic nature of the ion are such to stabilize the $\mathbf{Z 1}$ form also against the dissociation in the solution. This is in agreement with literature data on divalent cation complexation of quinolone antibiotics in aqueous solution. ${ }^{33,44,45}$ The present results show how a careful analysis of the gas-phase complexes can be instructive in order to assess and understand the solvent effects.

It also appears that larger monovalent metal ions can preferentially stabilize charge separated motifs. As already discussed for CIP $\mathrm{Ag}^{+}$and CIP $\mathrm{K}^{+}$, charge separation occurs in the CIP molecule, and the resulting negatively charged carboxylate binds to the metal ion. A variety of experimental studies have investigated the competition among nonionic and charge-separated structures in metal complexes of amino acids and peptides, considering the influence of both metal ion and ligand side chain. ${ }^{46-51}$

Frequency Trend. The analysis of the high frequency region of the IRMPD spectra reported in Figure 2 reveals a quite different behavior for the different metal ions.

As reported in the Discussion section, $\mathrm{Li}^{+}$and $\mathrm{Na}^{+}$cations prefer to coordinate the quinolone and carboxylic carbonyl groups of nonionic ciprofloxacin. This chelation pattern is characterized by the carboxylic $\mathrm{C}=\mathrm{O}$ stretching at approximately $1700 \mathrm{~cm}^{-1}$. The $\mathrm{C}=\mathrm{O}$ bond length is expected to increase and binding energy to weaken upon metalation. This explains the red shift of the carboxylic $\mathrm{C}=\mathrm{O}$ stretching of CIP when complexed when metal cations, as reported in Table 3. The red shift of this vibration increases with metal ion interaction, which is supposed to be larger when the distance among the metal ion and the carboxylic $\mathrm{CO}$ group decreases. The carboxylic $\mathrm{C}=\mathrm{O}$ stretching is found at $1762 \mathrm{~cm}^{-1}$ in $\mathrm{CIPH}^{+}$and red shifts to $1691 \mathrm{~cm}^{-1}$ in CIP $\mathrm{Li}^{+}$and to 1708 $\mathrm{cm}^{-1}$ in CIP $\mathrm{Na}^{+}$. The charge density of the lithium cation is greater than that of the sodium cation, resulting in greater charge transfer to the solvating carboxylic acid carbonyl and a corresponding greater shift in this band position for the lithiated species. Accordingly, the corresponding oxygen-metal distance is $1.84 \AA$ in $\mathrm{CIP}^{+}{ }^{+}$and $2.21 \AA \mathrm{CIP} \mathrm{Na}{ }^{+}$(see Figure 6 ). The predicted values for these frequencies match the same trend as reported in Table 3.

This trend is in agreement with that found for the shift of the $\mathrm{C}=\mathrm{O}$ stretching in complexes of amino acids and peptides with an alkali metal cation. ${ }^{46-51}$

In CIP $\mathrm{Mg}^{2+}\left(\mathrm{H}_{2} \mathrm{O}\right)_{3}$, the metal ion strongly coordinates only one of the two $\mathrm{CO}_{2}^{-}$oxygen atoms, breaking the symmetry of the carboxylate group. As shown in Figure 6, the typical $\mathrm{C} \cdots \mathrm{O}$ distance of the carboxylate group $(1.25 \AA)$ is not observed, and two different carbon-oxygen distances, that is, 1.29 and $1.22 \AA$, are found. For simplicity, the carboxylate group could be described as a deprotonated $\mathrm{CO}^{-}$coordinating the magnesium ion and a pure $\mathrm{C}=\mathrm{O}$ bond. This carboxylic $\mathrm{C}=\mathrm{O}$ stretching, which is not directly involved in the metal chelation, is predicted and experimentally found at $1716 \mathrm{~cm}^{-1}$, and a minor red shift is found with respect to $\mathrm{CIPH}^{+}$, despite the strong chelating power of $\mathrm{Mg}^{2+}$ ion.

Also, the quinolone carbonyl $\mathrm{C}=\mathrm{O}$ stretching vibration follows the same frequency trend versus the CIP-metal interaction, both for the experimental and the calculated values, as reported in Table 3. This stretching is found to red shift from approximately $1620 \mathrm{~cm}^{-1}$ in $\mathrm{CIPH}^{+}$to $1520 \mathrm{~cm}^{-1}$ in CIP $\mathrm{Mg}^{2+}\left(\mathrm{H}_{2} \mathrm{O}\right)_{3}$ and $1513 \mathrm{~cm}^{-1}$ in CIP $\mathrm{Li}^{+}$. Accordingly, the corresponding oxygen-metal distances are $1.79 \AA$ in $\mathrm{CIP} \mathrm{Li}^{+}$ and $1.99 \AA$ in $\mathrm{CIP} \mathrm{Mg}^{2+}\left(\mathrm{H}_{2} \mathrm{O}\right)_{3}$ (see Figure 6). In CIP Na${ }^{+}$, this distance raises to $2.16 \AA$, allowing to suppose a higher value of the quinolone carbonyl $\mathrm{C}=\mathrm{O}$ stretching frequency. The exact experimental value of this vibration cannot be detected in the IRMPD spectrum of CIP $\mathrm{Na}^{+}$(Figure 2), as the quinolone carbonyl $\mathrm{C}=\mathrm{O}$ stretching is smeared out together with other vibrational modes in a broad feature centered at $1490 \mathrm{~cm}^{-1}$ (see the Discussion section). However, the predicted value for the quinolone carbonyl $\mathrm{C}=\mathrm{O}$ stretching follows the expected trend.

For what concerns the CIP $\mathrm{Ag}^{+}$and CIP $\mathrm{K}^{+}$complexes, we reported in previous sections about their preference for the SC structure, in which the metal ion coordinates the deprotonated $\mathrm{CO}_{2}{ }^{-}$terminal and the resulting proton is attached on the adjacent quinolone carbonyl. Apart for the relative intensities, the spectra of these complexes are very similar (see Figure 2) and as expected do not have detectable absorptions in the region at approximately $1700 \mathrm{~cm}^{-1}$, which is diagnostic for the carboxylic $\mathrm{C}=\mathrm{O}$ stretching. The $\mathbf{S C}$ motif is characterized by the $\mathrm{C}-\mathrm{O}-\mathrm{H}$ bending and the $\mathrm{CO}_{2}^{-}$asymmetric and symmetric stretching. For both the CIP $\mathrm{Ag}^{+}$and the CIP $\mathrm{K}^{+}$ complexes, theoretical calculations predict two features in the high frequency region, approximately $30 \mathrm{~cm}^{-1}$ separated, due to the coupling of $\mathrm{C}-\mathrm{O}-\mathrm{H}$ bending, $\mathrm{CO}_{2}^{-}$asymmetric stretching and aromatic $\mathrm{C}-\mathrm{C}$ stretching. Nevertheless, the experimental spectra present a unique broad absorption, centered at $\sim 1615$ and $\sim 1608 \mathrm{~cm}^{-1}$ for the CIP $\mathrm{Ag}^{+}$and 
CIP $\mathrm{K}^{+}$complexes, respectively. We discussed in previous sections how this discrepancy could be due to anharmonic broadening effects in the absorption bands involving the $\mathrm{O} \cdots \mathrm{H}^{+} \cdots \mathrm{O}$ moiety. As known, ${ }^{41,42}$ the extent of the hydrogen bonding can be classified according to the distance between the oxygen atoms that share the proton: as this distance decreases, the potential energy barrier between the wells corresponding to the two positions for the proton becomes lower and the strength of the bond larger. For what concerns the $\mathrm{CO}_{2}{ }^{-}$ symmetric stretching, it falls in a spectral range characterized by a large number of skeletal modes and $\mathrm{CH}_{2}$ rocking, precluding the use of this vibration as a diagnostic of structural features.

The SC motif is characterized by an intramolecular hydrogen bond between the protonated hydroxyl group and the $\mathrm{CO}_{2}{ }^{-}$ group. The separations among the two oxygen atoms are predicted to be $2.54 \AA$ for $\mathrm{CIP} \mathrm{Ag}^{+}$and $2.50 \AA$ for $\mathrm{CIP} \mathrm{K}^{+}$, and the proton distances are as follows: $(\mathrm{O}-\mathrm{H})=1.00 \AA$ and $\mathrm{r}$ $(\mathrm{H} \cdots \mathrm{O})=1.63 \AA$ for $\mathrm{CIP} \mathrm{Ag}^{+} ; \mathrm{r}(\mathrm{O}-\mathrm{H})=1.02 \AA$ and $\mathrm{r}$ $(\mathrm{H} \cdots \mathrm{O})=1.55 \AA$ for $\mathrm{CIP} \mathrm{K}^{+}$(see Figure 6$)$. These distances are characteristic of a medium-strong hydrogen bonding that could justify the presence of a very anharmonic potential describing the motion of the proton.

As the experimental IRMPD spectra, the predicted IR frequencies, and the structural parameters are very similar for both the CIP $\mathrm{Ag}^{+}$and CIP $\mathrm{K}^{+}$complexes, it seems that the interactions of the two ions with the $\mathrm{CO}_{2}^{-}$group are very similar.

\section{CONCLUSIONS}

The IRMPD spectra of CIP metal complexes have been recorded in the $1000-1900 \mathrm{~cm}^{-1}$ range. The experimental results reported in the present work, in combination with quantum chemical calculations, provide for the first time important information on the gas-phase structural features of the metal coordination of this largely used quinolone antibiotic.

Different chelation motifs, that is, $\mathbf{M}, \mathbf{S C}, \mathbf{Z 1}$, and $\mathbf{Z 2}$, have been found depending on the metal ion size and charge. Small size and high charge density metal ions, that is, $\mathrm{Li}^{+}, \mathrm{Na}^{+}$, and $\mathrm{Mg}^{2+}\left(\mathrm{H}_{2} \mathrm{O}\right)_{3}$, prefer to coordinate the quinolone between the two carbonyl oxygen atoms (structures $\mathbf{M}$ and $\mathbf{Z 1}$ ), whereas large size metal ions, that is, $\mathrm{K}^{+}$and $\mathrm{Ag}^{+}$, prefer the carboxylate group as coordination site (structure $\mathbf{S C}$ ). In the latter case, an intramolecular hydrogen bond compensates for the weaker interaction established by these cations. No examples of $\mathbf{Z 2}$ structure have been found among the studied systems.

The IRMPD spectra of the adducts in the $\mathbf{M}$ and $\mathbf{Z 1}$ geometries are characterized by $\mathrm{C}=\mathrm{O}$ stretching, which matches very well with the theoretical calculations in the high frequency region. On the contrary, the two typical vibrations predicted in the IR spectra of the complexes with SC structure, that is, the asymmetric and symmetric stretching, are not found in the measured IRMPD spectra. By the experimental point of view, the latter falls in a spectral range characterized by a large number of skeletal modes and $\mathrm{CH}_{2}$ rocking, and the former is heavily influenced by the nearby presence of the anharmonic $\mathrm{OH}$ bending motion. Anyway, the broad spectral resonance found in the range $1500-1700 \mathrm{~cm}^{-1}$ for the absorption involving the $\mathrm{O} \cdots \mathrm{H}^{+} \cdots \mathrm{O}$ moiety produces a sort of fingerprint for the complexes in the SC geometry.

The competition among nonionic and charge-separated structures of CIP has been clearly highlighted by our results on CIP metal complexes. Large-size metal ions preferentially stabilize charge-separated motifs. The present study suggests indeed that increasing the metal ion formal charge has a stabilizing effect on the zwitterionic form of CIP. These results appear to confirm the trend found for metal complexes of amino acids and peptides.

The solvent effects on the stabilization of zwitterionic and nonzwitterionic structures of isolated and complexed CIP have been discussed. We found that, in the solution of the monovalent metal complexes, owing to the large stability of the CIP zwitterion in the solution, there is an almost complete dissociation of the $\mathbf{Z 1}$ and $\mathbf{Z 2}$ complexes with respect to the $\mathbf{M}$ and SC forms that remain bound and probably the only amenable of being detected in the gas phase. In the case of the magnesium complex, the strong increase in the density of positive charge in the $\mathbf{M}$ structure leads to a preferential stabilization of the zwitterionic moiety $\mathbf{Z 1}$ where the positive charge turns out less congested on one end of the molecule. It has been evidenced that the larger stability of the $\mathbf{Z 1}$ isomer in the case of the CIP $\mathrm{Mg}^{2+}\left(\mathrm{H}_{2} \mathrm{O}\right)_{3}$ complex does not depend on the presence of water molecules, also because they are bound to the metal ion and not to the CIP molecule.

\section{ASSOCIATED CONTENT}

\section{S Supporting Information}

Calculated spectra of the different isomers $\mathbf{M}, \mathbf{S C}, \mathbf{Z 2}$, and $\mathbf{Z 1}$ of CIP complexes with $\mathrm{Li}^{+},\left[\mathrm{Al}(\mathrm{OH})_{2}\right]^{+}$, and $\mathrm{Ag}^{+}$compared with the IRMPD experimental spectra. This material is available free of charge via the Internet at http://pubs.acs.org.

\section{AUTHOR INFORMATION}

\section{Corresponding Author}

*E-mail: alessandra.paladini@cnr.it. Fax: +390690672238. Phone: +3906 90672215 .

\section{Present Address}

${ }^{\#}$ ENEA, C.R. Frascati, Via E. Fermi 45, 00044 Frascati (RM), Italy.

Notes

The authors declare no competing financial interest.

\section{ACKNOWLEDGMENTS}

The research leading to these results has received funding from the European Union's Seventh Framework Programme (FP7/ 2007-2013) under grant agreement no. 226716 and the PRIN grant no. 2009SLKFEX (MIUR). The authors acknowledge Daniele Catone for software development. Thanks are due to Anna Giardini and Philippe Maitre for helpful discussions. JeanMichel Ortega and the CLIO staff are gratefully acknowledged for their assistance. E.B. acknowledges the CASPUR and CINECA calculation support through the std11-424 and IscrB_ASIL grants, respectively.

\section{REFERENCES}

(1) Quinolone Antimicrobial Agents, 3rd ed.; Hooper, D. C., Rubinstein, E., Eds.; ASM Press: Washington, DC, 2003.

(2) The Quinolones, 3rd ed.; Andriole, V. T., Ed.; Academic Press: San Diego, CA, 2000.

(3) Drlica, K.; Zhao, X. Microbiol. Mol. Biol. Rev. 1997, 61, 377-392.

(4) Polk, R. E.; Healy, D. P.; Sahai, J.; Drwal, L.; Racht, E. Antimicrob. Agents Chemother. 1989, 33, 1841-1844.

(5) Marchbanks, C. R. Pharmacotherapy 1993, 13, 23S-28S.

(6) Stein, G. E. Am. J. Med. 1991, 91, S81-S86.

(7) Rubistein, E.; Segev, S. Am. J. Med. 1987, 82, 119-123.

(8) Ortega, J. M.; Glotin, F.; Prazeres, R. Infrared Phys. Technol. 2006, 49, 133-138. 
(9) MacAleese, L.; Maître, P. Mass Spectrom. Rev. 2007, 26, 583-605.

(10) Filippi, A.; Fraschetti, C.; Piccirillo, S.; Rondino, F.; Botta, B.; D'Acquarica, I.; Calcaterra, A.; Speranza, M. Chem.-Eur. J. 2012, 18, $8320-8328$.

(11) Bakker, J. M.; Besson, T.; Lemaire, J.; Scuderi, D.; Maître, P. J. Phys. Chem. A 2007, 111, 13415-24.

(12) Sinha, R. K.; Maitre, P.; Piccirillo, S.; Chiavarino, B.; Crestoni,

M. E.; Fornarini, S. Phys. Chem. Chem. Phys. 2010, 12, 9794-9800.

(13) Fridgen, T. D. Mass Spectrom. Rev. 2009, 28, 586-607.

(14) Polfer, N. C.; Oomens, J. Mass Spectrom. Rev. 2009, 28, 468494.

(15) Oomens, J.; Sartakov, B. G.; Meijer, G.; von Helden, G. Int. J. Mass Spectrom. 2006, 254, 1-19.

(16) Walker, N. R.; Walters, R. S.; Duncan, M. A. New J. Chem. 2005, 29, 1495-1503.

(17) Polfer, N. C.; Oomens, J.; Dunbar, R. C. Phys. Chem. Chem. Phys. 2006, 8, 2744-2751.

(18) Lucas, B.; Grégoire, G.; Lemaire, J.; Maître, P.; Glotin, F.; Schermann, J. P.; Desfrançois, C. Int. J. Mass Spectrom. 2008, 243, 97105.

(19) Dunbar, R. C.; Polfer, N. C.; Oomens, J. J. Am. Chem. Soc. 2007, $129,14562$.

(20) Balaj, O. P.; Kapota, C.; Lemaire, J.; Ohanessian, G. Int. J. Mass Spectrom. 2008, 269, 196.

(21) Bush, M. F.; Oomens, J.; Saykally, R. J.; Williams, E. R. J. Am. Chem. Soc. 2008, 130, 6463.

(22) Gillis, E. A. L.; Rajabi, K.; Fridgen, T. D. J. Phys. Chem. A 2009, $113,824$.

(23) Bodo, E.; Ciavardini, A.; Giardini, A.; Paladini, A.; Piccirillo, S.; Rondino, F.; Scuderi, D. Chem. Phys. 2012, 398, 124-128.

(24) Tian, Z.; Kass, S. R. Angew. Chem. 2009, 121, 1347.

(25) Steill, J. D.; Oomens, J. J. Am. Chem. Soc. 2009, 131, 13570.

(26) Frisch, M. J.; Trucks, G. W.; Schlegel, H. B.; Scuseria, G. E.; Robb, M. A.; Cheeseman, J. R.; Scalmani, G.; Barone, V.; Mennucci, B.; Petersson, G. A.; Nakatsuji, H.; Caricato, M.; Li, X.; Hratchian, H. P.; Izmaylov, A. F.; Bloino, J.; Zheng, G.; Sonnenberg, J. L.; Hada, M.; Ehara, M.; Toyota, K.; Fukuda, R.; Hasegawa, J.; Ishida, M.; Nakajima, T.; Honda, Y.; Kitao, O.; Nakai, H.; Vreven, T.; Montgomery, Jr., J. A.; Peralta, J. E.; Ogliaro, F.; Bearpark, M.; Heyd, J. J.; Brothers, E.; Kudin, K. N.; Staroverov, V. N.; Kobayashi, R.; Normand, J.; Raghavachari, K.; Rendell, A.; Burant, J. C.; Iyengar, S. S.; Tomasi, J.; Cossi, M.; Rega, N.; Millam, J. M.; Klene, M.; Knox, J. E.; Cross, J. B.; Bakken, V.; Adamo, C.; Jaramillo, J.; Gomperts, R.; Stratmann, R. E.; Yazyev, O.; Austin, A. J.; Cammi, R.; Pomelli, C.; Ochterski, J. W.; Martin, R. L.; Morokuma, K.; Zakrzewski, V. G.; Voth, G. A.; Salvador, P.; Dannenberg, J. J.; Dapprich, S.; Daniels, A. D.; Farkas, Ö., Foresman, J. B.; Ortiz, J. V.; Cioslowski, J.; Fox, D. J. Gaussian 09, Revision A.1; Gaussian, Inc.: Wallingford, CT, 2009.

(27) Carl, D. R.; Cooper, T. E.; Oomens, J.; Steill, J. D.; Armentrout, P. B. Phys. Chem. Chem. Phys. 2010, 12, 3384-3398.

(28) Dunbar, R. C.; Steill, J. D.; Polfer, N. C.; Oomens, J. J. Phys. Chem. A 2009, 113, 845-851.

(29) Heaton, A. L.; Bowman, V. N.; Oomens, J.; Steill, J. D.; Armentrout, P. B. J. Phys. Chem. A 2009, 113, 5519-5530.

(30) Bush, M. F.; Oomens, J.; Saykally, R. J.; Williams, E. R. J. Phys. Chem. A 2008, 112, 8578-8584.

(31) Mac Aleese, L.; Simon, A.; McMahon, T. B.; Ortega, J. M.; Scuderi, D.; Lemaire, J.; Maitre, P. Int. J. Mass Spectrom. 2006, 249, $14-20$.

(32) Boys, S. F.; Bernardi, F. Mol. Phys. 1970, 19, 553.

(33) Okabayashi, Y.; Hayashi, F.; Terui, Y.; Kitagawa, T. Chem. Pharm. Bull. 1992, 40, 692-696.

(34) Lemaire, J.; Boissel, P.; Heninger, M.; Mauclaire, G.; Bellec, G.; Mestdagh, H.; Simon, A.; Caer, S. L.; Ortega, J. M.; Glotin, F.; Maître, P. Phys. Rev. Lett. 2002, 89, 273002.

(35) At variance with CIP $\mathrm{Na}^{+}$and CIP $\mathrm{K}^{+}$, the depletion spectrum of $\mathrm{CIP} \mathrm{Li}^{+}$could not be compared as such with the calculated IR spectrum, as it presents a very broaden profile in the range 1200-1800 $\mathrm{cm}^{-1}$ and its intensity is very low.
(36) Nesbitt, D. J.; Field, R. W. J. Phys. Chem. 1996, 100, 12765.

(37) Oomens, J.; Tielens, A. G. G. M.; Sartokov, B.; von Helden, G.; Meijer, G. Astrophys. J. 2003, 591, 968-985.

(38) Oomens, J.; Steill, J. D.; Redlich, B. J. Am. Chem. Soc. 2009, 131, $4310-4319$.

(39) Oomens, J.; Sartakov, B. G.; Tielens, A. G. G. M.; Meijer, G.; von Helden, G. Astrophys. J. 2001, 560, L99-L103.

(40) Joblin, C.; Boissel, P.; Léger, A.; d'Hendecourt, L.; Défourneau, D. Astron. Astrophys. 1995, 299, 835-846.

(41) Moore, D. T.; Oomens, J.; van der Meer, L.; von Helden, G.; Meijer, G.; Valle, J.; Marshall, A. G.; Eyler, J. R. ChemPhysChem 2004, $5,740-743$.

(42) Gilli, P.; Bertolasi, V.; Ferretti, V.; Gilli, G. J. Am. Chem. Soc. 1994, 116, 909-915.

(43) Turel, I. Coord. Chem. Rev. 2001, 232, 27-47.

(44) Park, H.-R.; Chung, K.-Y.; Lee, H.-C.; Lee, J.-K.; Bark, K.-M. Bull. Korean Chem. Soc. 2000, 21, 849-854.

(45) Kawai, Y.; Matsubayashi, K.; Hakusui, H. Chem. Pharm. Bull. 1996, 44, 1425-1430.

(46) Dunbar, R. C.; Steill, J. D.; Oomens, J. Phys. Chem. Chem. Phys. 2010, 12, 13383-13393.

(47) Bush, M. F.; Forbes, M. W.; Jockusch, R. A.; Oomens, J.; Polfer, N.; Saykally, R. J.; Williams, E. R. J. Phys. Chem. A 2007, 111, 77537760.

(48) Dunbar, R. C.; Steill, J. D.; Oomens, J. J. Am. Chem. Soc. 2011, 133, 9376-9386.

(49) Dray $\beta$, M. K.; Armentrout, P. B.; Oomens, J.; Schäfer, M. Int. J. Mass Spectrom. 2010, 297, 18-27.

(50) Moision, R. M.; Armentrout, P. B. J. Phys. Chem. A 2006, 110, 3933-3943.

(51) Polfer, N. C.; Oomens, J.; Dunbar, R. C. ChemPhysChem 2008, $9,579$. 